\title{
Effects of 12 hour calf withdrawal on conception rate and calf performance of Bos indicus cattle under extensive conditions
}

\author{
R. J. A. Escrivão ${ }^{1}$, E. C. Webb ${ }^{2}$ and A. P. J. T. Garcês ${ }^{1}$
}

(1) Department of Animal Production, Faculty of Veterinary, Eduardo Mondlane University, Maputo, Mozambique

(2) Department of Animal and Wildlife Sciences, University of Pretoria, Pretoria, 0002, South Africa

R. J. A. Escrivão

Email: rafael.escrivao@uem.mz

\section{Abstract}

Fifty-two multiparous Brahman type cows with reproductive tract scoring (RTS) $\geq 4$ at 45 days post-partum were randomly assigned to two groups of 26 cows each separated into an ad libitum suckling group (C) and treatment group (T). Calves in the T group were separated for $12 \mathrm{~h}$ during the night from 45 days post-partum to the onset of the breeding season. Body condition score (BCS) and body weight (BW) were recorded 45 days post-partum, at the start of the breeding season, and at pregnancy diagnosis. Calves were weighed at calving and weaning. Weaning weights were corrected to 205 days. BW and BCS at the onset of the breeding season were similar $(\mathrm{p}>0.05)$ between the experimental groups. Calving to breeding intervals were $93 \pm 18 \mathrm{~d}$ and $99 \pm 22$ $\mathrm{d}$ for $\mathrm{T}$ and $\mathrm{C}$ groups, respectively. Calving to conception intervals differed significantly between the groups $(111 \pm 10 \mathrm{~d}$ for $\mathrm{T}$ and $133 \pm 19 \mathrm{~d}$ for $\mathrm{C})$ and a similar result was obtained for the breeding to conception intervals ( $18 \pm 15 \mathrm{~d}$ for $\mathrm{T}$ and $31 \pm 19 \mathrm{~d}$ for $\mathrm{C}$ ). Conception rates were $80 \%$ for the T group and 59\% for the $\mathrm{C}$ group, which correlated better with BW than BCS at the onset of the breeding season. Weaning weights differed $(\mathrm{p}<0.05)$ between $\mathrm{C}$ and $\mathrm{T}$ groups. From 45 days post-partum to the onset of the breeding season, cows in the $\mathrm{T}$ group experienced a positive energy balance $(3 \%)$ while those in the $\mathrm{C}$ group had a negative energy balance $(-0.1 \%)$. It was concluded that $12 \mathrm{~h}$ calf separation at night increases the conception rates and improves the calf weaning weights of Bos indicus beef cattle under extensive production systems in sub-tropical conditions.

Abbreviations $B C S$ body condition score - $B W$ body weight - $B_{w}$ birth weight $B C I$ breeding to conception interval - $C$ control group - $C B I$ calving to breeding interval $C C I$ calving to conception interval - $C R$ conception rate - $R T S$ reproductive tract score $T$ treatment groupIntroduction 


\section{Introduction}

Suckling has been reported to prolong the post-partum anestrus, probably through a neural-mediated inhibition of LHRH, or the inhibitory effect of RH on gonadotrophins, or action on the ovary (Convey et al. 1983; Pérez-Hernández et al. 2002). Notwithstanding the evidence that suckling may act in a chronic fashion to inhibit LH secretion during post-partum period, the exact mode of action by which suckling extends post-partum anestrus is uncertain (Crowe et al. 1998; Pérez-Hernández et al. 2002).

Suckling may occur 6 to 9 times a day, with young calves suckling more frequently than older calves (Stewart et al. 1993a; Gazal et al. 1999; Das et al. 2000; Paranhos da Costa et al. 2006). Suckling frequency appears to be the characteristic that correlates best with anticipated onset of estrus in the post-partum period (Stewart et al. 1993b; Lamb et al. 1999; Gazal et al. 1999; Morongiu et al. 2002). In rodents it was shown that the inhibitory effect is directly related to suckling intensity (Ford and Melamphy 1973; Hammons et al. 1973).

Separation of a calf from its dam for 12 hours each day shortens the interval to first estrus post-partum and increases the conception rate of Bos taurus beef cows in intensive production systems (Stewart et al. 1993b; Gazal et al. 1999). There is however no information on $12 \mathrm{~h}$ calf separation in Bos indicus cows under extensive production systems in sub-tropical conditions as well as the influence of calf separation on the weaning weights of calves. The present study was thus conducted to determine if restricted suckling at night from 45 days post-partum increases the conception rate in Bos indicus beef cows under extensive production systems and to quantify the related effects on calf weaning weights.

\section{Materials and methods}

The experiment was carried out at the Inácio de Sousa extensive beef cattle farm located in Manhiça district, about $100 \mathrm{~km}$ to the north of Maputo city, in Mozambique. The climate at this location is sub-tropical humid, with an average temperature of $28^{\circ} \mathrm{C}$ and average annual rainfall of $950 \mathrm{~mm}$. About $80 \%$ of the rainfall is concentrated during the rainy season that last for 6 months (October to March), with $50 \%$ of the rain distributed between December and January.

Fifty two multiparous Brahman type cows were randomly allotted from a group of postpartum cows that had all calved during the calving season (October to December), normal parturition, irrespective of the sex of their calves. The cows were randomly assigned to two groups of 26 cows each (treatment and control groups). Reproductive tract scoring (RTS) was performed at 45 days post-partum (calculated based on the actual calving dates) via rectal palpation using a 5 point cows' reproductive tract scoring method as described by Schwalbach et al. (2000). Only cows with a RTS of 4 or above were incorporated in the experiment. 
Cows were maintained in the herd under the same management as the whole farm, taken to grazing areas between 7:00 and 17:00, without supplementary feeding and calves from the treatment group were removed at 18:00 after the herd returned to the coral.

Separation of calves for a period of $12 \mathrm{~h}$ (12 h night-calf-separation; 18:00 to 6:00) began 45 days post-partum until the beginning of the breeding season and then calves were allowed to suckle ad libitum. Calves from the control group remained with their dams for the entire period. Breeding soundness examinations were performed using the system of Hopkins and Spitzer (1997) and only satisfactory classified bulls were used at a ratio of 1:20 cows for a breeding season of 90 days (January to March).

The post-partum interval to the start of the breeding season (CBI) and the duration of treatment were calculated. Body weight was recorded using a standard scale for cattle 45 days post-partum, at the onset of the breeding season and during pregnancy diagnosis along with the BCS determinations. BCS determinations were done using a 5 point Scottish scoring method (Wiltbank 1991). The energy balance of the cows (weight loss or weight gain) at the onset of the breeding season was calculated and expressed as percentage. Pregnancy diagnosis took place 60 days after the end of the breeding season. Pregnant cows were monitored to the end of the gestation period, and calving dates were recorded. Calving intervals $(\mathrm{CI})$ were calculated and then used to calculate the calving to conception intervals (CCI) and breeding to conception intervals (BCI), as follows:

\section{$\mathrm{CT}=\mathrm{CT}-\mathrm{seg} d x \mathrm{C}$ \\ $\mathrm{BCT}=\mathrm{COT}-\mathrm{CBI}$}

The weights of the calves were recorded at calving, within $48 \mathrm{~h}$ of parturition and at weaning.

As calving dates differed marginally, but all calves were weaned on the same day, a correction factor was included to correct for these differences in weaning weights. Weaning weight was corrected to 205 days using the following formula:

\section{$\left.\left.\mathrm{C}_{\mathrm{w} w}=\mathrm{B}_{w}+\left[\left(\mathrm{W}_{w}-\mathrm{B}_{w}\right) / \mathrm{W}_{w}\right) * 200\right)\right]$}

Where:

$C_{w w} \quad$ Corrected weaning weight

$B_{w} \quad$ Birth weight

$W_{w} \quad$ Weaning weight

$W_{a} \quad$ Weaning age

Data was analyzed using the analysis of variance (ANOVA) procedure in SPSS version 14.0 for Windows, by including treatment group as fixed factor in the model and the variables $\mathrm{BW}, \mathrm{BCS}$, energy balance, pregnancy status, post-partum interval to breeding, birth weights, corrected weaning weight and the corresponding interactions. Pearson product moment correlation coefficients were calculated between variables as well as the significance levels. Differences between factors were assessed at a significance level of $\mathrm{p}<0.05$ (95\% accuracy). All results were expressed as least square means (LSmeans) \pm standard deviation (SD) and multiple comparisons of means were done by means of the Bonferroni method in order to correct for unbalanced data, where the number of 
observations differed. Pregnancy status of treated and control cows were compared by Chi-square analyse (SPSS 2005).

\section{Results and discussion}

Cows incorporated in the present study showed at 45 days post-partum the following reproductive tract characteristics: Vulva and vagina were normal with most pink mucosa, intra-pelvic location of the cervix, involuted uterus and approximately symmetric and tin wall without content, good tone and active ovaries with either follicle or corpus luteum. The BW and BCS of cows in the experimental groups were typical for Brahman type cows under extensive production system in Mozambique (Schwalbach et al. 1997), taking into consideration the physiological status of the cows and season of the year.

From calving to breeding, the available forage increased in both quantity and quality as a result of the seasonal variation on forage production associated with the sub-tropical climate. Nevertheless cows in the control group experienced a negative energy balance though the BSC were similar (Table 1).

Table 1 The mean $( \pm$ SD) effect of $12 \mathrm{~h}$ calf withdrawal at night on production and reproduction characteristics of Bos indicus cows and calves

\begin{tabular}{|l|l|l|}
\hline \multirow{2}{*}{ Trait } & \multicolumn{2}{c|}{ Group } \\
& Treatment & Control \\
\hline Body weight $(\mathrm{Kg})^{*}$ & $396 \pm 50$ & $411 \pm 40$ \\
\hline Body condition score* & $2.5 \pm 0.3$ & $2.6 \pm 0.3$ \\
\hline Energy balance $(\mathrm{Kg})^{*}$ & $12 \pm 10^{\mathrm{a}}(3 \%)$ & $-0.4 \pm 12^{\mathrm{b}}(-0.1 \%)$ \\
\hline Birth weigth (kg) & $28.3 \pm 0.9$ & $28.5 \pm 0.9$ \\
\hline Corrected weaning weight $(\mathrm{Kg})$ & $149.3 \pm 18^{\mathrm{a}}$ & $134.5 \pm 20^{\mathrm{b}}$ \\
\hline Calving to breeding interval (days) & $93 \pm 18$ & $99 \pm 22$ \\
\hline Calving to conception interval (days) & $111 \pm 10^{\mathrm{a}}$ & $133 \pm 19^{\mathrm{b}}$ \\
\hline Breeding to conception interval (days) & $18 \pm 15^{\mathrm{a}}$ & $31 \pm 17.3^{\mathrm{b}}$ \\
\hline Conception rate (\%) & 80 & \multicolumn{1}{|c|}{59} \\
\hline
\end{tabular}

*At the start of the breeding season

${ }^{\mathrm{a}, \mathrm{b}}$ Means with different superscripts in the same row differ significantly $(\mathrm{p}<0.05)$ Under the true extensive production system with minimal management on which the experiment took place the BW, BCS and energy balance of cows at the start of the breeding season and, birth weights of calves, corrected weaning weights, calving to breeding interval, breeding to conception interval and conception rates are summarized in Table 1. 
The present study was conducted on Bos indicus beef cattle with the $12 \mathrm{~h}$ night-calf removal for $48 \pm 18$ days prior to the breeding season under extensive production system in sub-tropical region. Previous studies were performed on Bos taurus beef cattle within weeks prior to the onset of the breeding season (Stewart et al. 1993b) and in crossbreed Bos taurus $x$ Bos indicus beef cattle from 9 to 12 days post-partum to first luteal phase or 100 days post-partum in intensive production systems (Gazal et al. 1999).

The conception rates were $80 \%$ for the treatment group and $59 \%$ for the control group. Although the conception rates did not differ $(\mathrm{p}>0.05)$ between groups, but the numerical difference of almost $20 \%$ was considerable (Table 1). The observed numerical increase in conception rates for cows in the treatment group agrees with the results of Stewart et al. (1993b) but contrast with those from Gazal et al. (1999) who reported that $12 \mathrm{~h}$ (night or day) calf separation did not affect the duration of post-partum anestrus. The agreement with Stewart's results is probable due to the fact that both experiments were performed in sub-tropical conditions and prior to breeding season though the breed type differed significantly. In addition, results of the present study indicated that by performing a $12 \mathrm{~h}$ calf withdrawal at night there is an increase on BW of cows with consequent positive energy balance $(3 \%)$ which if combined with the reduced teat stimulation frequency triggered the hypothamuls-ovarian function (BCI of $18 \pm 15$ days). The ad libitum suckling group had a conception rate of about 59\% which concurs with the previous results of Escrivão 2005 (unpublished report) for extensive beef cattle in the south of Mozambique.

Like BW and BCS at the onset of the breeding season, $\mathrm{CBI}$ is an important predictor of pregnancy rate. In the present study, conception rates were affected $(p<0.05)$ by CBI, which concur with the findings in literature (Requist et al. 2006) but, the treatment effects were stronger because the conception rates were higher for cows in the treatment group and they had a shorter CBI. The BCI of cows in the treatment group was only $18 \pm 15$ days, which represent a meaningful improvement in reproductive efficiency of extensive beef cattle, where the norm is in the order of $31 \pm 17$ days (control group). This improvement is probably due to the fact that cows in the treatment group calved earlier in the calving season, weaned a heavier calf and had enough time to recover for the following breeding season. These results agree with those of Stewart et al. (1993b) where $56.8 \%$ of the day-suckled cows showed estrus activity during the first 30 days of the breeding season, compared to $22 \%$ of the night suckling cows.

In the current study, weaning weights increased $(\mathrm{p}<0.05)$ with $12 \mathrm{~h}$ night-calf removal, contrary to the common belief. A number of reports in the literature suggest that temporarily calf removal do not affect the weaning weights of calves (Bell et al. 1998). The finding in the present study that $12 \mathrm{~h}$ calf withdrawal has a positive effect on weaning weights of calves is probably because of the period of calf removal coinciding with the availability of good green pastures and calves making better use of it and compensatory growth seems to play a role.

The correlations observed between BCS, BW, energy balance at the start of the breeding season and conceptions rates demonstrated the importance of these variables in terms of 
reproduction. Results of the present study agree with those of other studies (Osoro and Wright 1992; DeRouen et al. 1994; Morrison et al. 1999). Although animal scientists and veterinarians use BCS more often than BW in their routine work, this study indicated that BW is the most appropriate indicator of body energy reserves and re-breeding performance of Bos indicus beef cows under extensive production systems in sub-tropic conditions.

\section{Conclusions}

Twelve hours calf removal at night for 48 days prior to the breeding season increases the percentage of cows that exhibit estrus within the first 21 days of the breeding season, enhance conception rates and has a beneficial effect on calf weaning weights of Bos indicus beef cattle in extensive production systems.

\section{References}

Bell, D. J., Spitzer, J. C., \& Bums, G. L. (1998). Comparative effects of early weaning or once daily-suckling on occurrence of post-partum estrus in primiparouos beef cows. Theriogenology, 50(5), 701-715.

Convey, E. M., Tucker, H. A., \& Short, R. E. (1983). Acute effect of suckling on gonadotrophin ,prolatin and glucocorticoid concentration in serum of intact and ovariectomized beef cows. Theriogenology, 20(6), 661-674.

Crowe, M. A., Padmanaban, V., Mihm, M., Beitins, I. Z., \& Roche, J. F. (1998). Resumption of follicular waves in beef cows is not associated with periparturient changes in follicle- stimulating hormone heterogeneity despite major changes in steroid and luteinizing hormone concentrations. Biology of Reproduction, 58, 1445-1450.

Das, S. M., Redbo, I., \& Wiktorsson, H. (2000). Effect of age of calf on suckling behaviour and other behavioural activities of zebu and crossbreed calves during restricted suckling periods. Applied Animal Behavior Science, 67, 47-57.

DeRouen, S. M., Franke, D. E., Morrison, D. G., Wyatt, W. E., Coombs, D. F., White, T., et al. (1994). Prepartum body condition and weight influences on reproductive performance of first-calf beef cows. Journal of Animal Science, 72, 1119-1125.

Ford, J. J., \& Melampy, R. M. (1973). Gonadotropin level in lactating rats: effect of ovariectomy. Endocrinology, 93, 540-547 (cited by Garcia- Winder et al. 1986).

Gazal, O. S., Guzman-Vega, G. A., \& Williams, G. L. (1999). Effects of time of suckling during the solar day on duration of the postpartum anovulatory interval in Brahaman $\mathrm{X}$ 
Hereford (F1) cows. Journal of Animal Science, 77, 1044-1047.

Hopkins, F. M., Spitzer, J. C. (1997). The new society for theriogenology breeding soundness evaluation system. Theriogenology, 13(2), 283-293.

Hammons, J. M., Velasco, M., \& Rothchild, I. (1973). Effect of sudden withdrawal or increase in suckling on serum LH levels in ovariectomized postparturient rats.

Endocrinology, 92, 206-211, (cited by Garcia-Winder et al. 1986).

Lamb, G. C., Miller, B. L., Lynch, J. M., Thompson, K. E., Heldt, J. S., Loest, C. A., et al. (1999). Twice daily suckling but not milking with calf presence prolongs postpartum anovulation. Journal of Animal Science, 77, 2207-2218.

Morongiu, M. L., Molle, G., San Juan, L., Bomboi, G., Ligios, C., Sanna, A., et al. (2002). Effects of feeding level before and after calving, and restricted suckling frequency on postpartum reproductive and productive performance of Sarda and Charolais X Sarda beef cows. Livestock Production Science, 77, 339-348.

Morrison, D. G., Spitzer, J. C., \& Perkins, J. L. (1999). Influence of prepartum body condition score change on reproduction in multiparous beef cows calving in moderate body condition score. Journal of animal Science, 77, 1048-1053.

Osoro, K., \& Writght, I. A. (1992). The effect of body condition, live weight, breed, age, calf performance and calving date on reproductive performance of spring-calving beef cows. Journal of Animal Science, 70, 1661-1666.

Paranhos da Costa, M. J. R., Albuquerque, L. G., Eler, J. P., \& Silva, J. A. V. II (2006). Suckling behaviour of Nelore, Gir and Caracu calves and their crosses. Applied Animal Behavior Science, 101, 276-287.

Pérez-Hernández, P., Garcia-Winder, M., \& Gallegos- Sanchez, J. (2002). Postpartum anoestrus is reduced by increasing the within-day milking to suckling interval in dual purpose cows. Animal Reproduction Science, 73, 159-168.

Requist, B. J., Oltjen, J. W., Sainz, R. D., \& Calvert, C. C. (2006). Relationship between body condition score and production of multiparous beef cows. Livestock Science, 104, $147-155$.

SPSS (2005). SPSS version 14.0 for Windows. SPSS Inc. USA (http://www.spss.com) 
Stewart, I. B., Louw, B. P., \& Lishman, A. W. (1993a). Suckling behaviour and fertility in beef cows on pasture, 1. Suckling behaviour. South African Journal of Animal Science, 23(5/6), 176-179.

Stewart, I. B., Louw, B. P., \& Lishman, A. W. (1993b). Suckling behaviour and fertility in beef cows on pasture, 2. Influence of twelve hours calf separation on interval to first oestrus after onset of mating pariod. South African Journal of Animal Science, 23(5/6), $180-182$.

Schwalbach, L. M. J., Greyling, J. P. C., \& Taylor, G. J. (2000). Postpartum reproductive tract score in beef cows - a proposed method. South African Journal of Animal Science, suppl, 1120-121.

Schwalbach, L. M. J., Lopes Pereira, C. M., Escrivão, R. J. A., \& Mota Cardoso, J. M. (1997). Determination of body condition and its relation with fertility in five beef cattle farms in Mozambique. Veterinária Tecnica, 5, 18-20.

Wiltbank, J. N. (1991). Body condition score in beef cattle. In: J. M. Naylor, S. L. Ralston (Ed.), Large Animal Clinical Nutrition (pp. 196-178). Year Book Inc.: Baltimore Mosby. 